\title{
El capitalismo periférico alemán en el Desierto de Atacama en el siglo XXI*
}

\section{The german peripheric capitalism in the Atacama Desert in the Nineteenth Century}

\author{
José Antonio González Pizarro** \\ Facultad de Ciencias Jurídicas \\ Universidad Católica del Norte, Chile. \\ Marcelo Lufin Varas*** \\ Facultad de Economía y Administración \\ Universidad Católica del Norte, Chile. \\ Claudio Galeno Ibaceta**** \\ Escuela de Arquitectura \\ Universidad Católica del Norte, Chile.
}

Recibido: 12 de mayo de 2017. Aprobado: 15 de enero de 2018.

\section{Resumen}

El trabajo explica el proceso migratorio alemán en el desierto de Atacama, principalmente en torno a la ciudad de Antofagasta, cuando surgía la explotación salitrera y de plata. En esta perspectiva, se rescata la desconocida influencia germana

* Proyecto Fondecyt 1130785

** Doctor en Historia. Universidad de Navarra. Director del Centro de Estudios Histórico-Jurídicos de la Facultad de Ciencias Jurídicas de la Universidad Católica del Norte, Antofagasta, Chile. E-mail: jagonzal@ucn.cl

*** Doctor en Planificación Regional. Universidad de Illinois. Director del Observatorio Regional de la Migración de la Facultad de Economía y Administración de la Universidad Católica del Norte, Antofagasta, Chile.E-mail: mlufin@ucn.cl.

${ }^{* * * *}$ Doctor en Teoría e Historia de la Arquitectura. Universidad Politécnica de Cataluña. Académico Escuela de Arquitectura y Magíster en Arquitectura, Universidad Católica del Norte, Antofagasta, Chile. E-mail: cgaleno@ucn.cl 
en el proceso de institucionalización y en el fomento de las actividades comerciales en el nuevo asentamiento. Los alemanes lograron establecer una interesante red social en Antofagasta. A partir de este núcleo, los inmigrantes pudieron informarse de la geografía adversa pero también de las oportunidades que se ofrecían en una sociedad en formación, en negocios múltiples y en un mercado laboral dinámico. También incursionaron en el ámbito político. Todo esto se vio impulsado por factores políticos y económicos que el liberalismo en Chile incentivó.

Palabras claves: alemanes, desierto, comercio.

\begin{abstract}
This paper describes the German migration process in the Atacama Desert, mainly around the city of Antofagasta, during the early period of nitrate and silver exploitation. Germany's previously unrecognized influence is described as part of the process of institutionalization and promotion of business activities in the new settlement. The Germans successfully established an interesting social network in Antofagasta that allowed immigrants to learn about the area's inhospitable geography as well as the opportunities available in various fields and in a dynamic labor market. Members of this community also ventured into the political arena. All of this was encouraged by political and economic factors stimulated by liberalism in Chile.
\end{abstract}

Keywords: germans, desert, business

\title{
Introducción
}

La inmigración alemana en Chile se concentró, tanto por su localización física e impacto comercial, en la parte meridional del territorio. Nuestra historiografía ha develado su presencia en las ciudades de mayor envergadura, como Santiago o Valparaíso y, principalmente, en ciudades del extremo sur, como Valdivia u Osorno. No obstante, el examen documental del flujo migratorio en el desierto de Atacama durante el periodo clásico del salitre permite adicionar a la ciudad de Antofagasta, 
como un importante lugar en el siglo XIX que llamó la atención a los alemanes.

¿Cómo se pudo plantear una aventura en un territorio inhóspito y distante de los centros urbanos más importantes de Chile como de Bolivia? ¿Ayudó la llegada de los comerciantes a estimular el arribo de otros connacionales? ¿Es posible afirmar que las políticas europeas de liberalismo poblacional coincidente con los flujos de capitales hacia ultramar, coadyuvaron a decidir a la migración germana a procurar un espacio en el lejano desierto de Atacama, por el doble reto de riesgo empresarial y posibilidad de concretar proyectos personales/familiares?

Podríamos formular que las actividades comerciales germanas en el desierto de Atacama permiten encontrar cierta homologación en cuanto a su relevancia a lo realizado en el extremo sur. Ambos grupos enfrentaron la adversidad geográfica -aunque el sur más próxima al paisaje europeo- y también contribuyeron a moldear la fisonomía funcional urbana y contribuir al progreso social. Mucho más profunda y decidora en la parte meridional. En el caso de Antofagasta, junto con otras colonias de inmigrantes, los alemanes dotaron de un aire cosmopolita y globalizante a la ciudad de Antofagasta. Y también no se inhibieron de participar en la política local y regional, junto con los mineros y comerciantes extranjeros (chilenos en su gran mayoría durante la administración boliviana del territorio), en Antofagasta y en el mineral de Caracoles.

La presencia alemana ha sido ignorada en los estudios sobre los alemanes en el norte de Chile. Cabe acotar que la migración germana se vio reforzada por el prestigio que asumió la Alemania unificada bajo el Imperio, en los distintos ámbitos de la ciencia, la tecnología, la cultura y el comercio.

La importancia de este trabajo radica en la introducción de los alemanes en una zona totalmente alejada del paisaje de su procedencia geográfica y su incursión en las actividades mineras en el desierto de Atacama. 


\section{Algunas características de la población alemana en Chile}

Al despuntar el siglo XX la política alemana hacia América Latina se había manifestado en una profundización de los intereses económicos, mediante inversiones o aumento de los flujos comerciales o bien por medio de la cultura, como ser estudios en las ciencias humanas, presencia de investigadores y eruditos para incidir en la orientación bajo el espíritu alemán (Penny, 2002; Rebok, 2002). Y como ha resaltado Sanhueza (2006), las impresiones de los viajeros chilenos reforzaban el papel de Alemania en una orientación cultural diferente a Francia. En nuestro país, a diferencia del continente latinoamericano, la influencia castrense se hizo notar (Blancpain, 1974; Brahm, 2003; Rebok, 2002; Rinke, 2014). Si bien, los Estados Unidos de América y Brasil fueron los países que concentraron el flujo migratorio alemán en el continente, Argentina y Chile contaron con una no despreciable afluencia de colonos alemanes y en menor intensidad Colombia y Venezuela (Güenaga, 1989; Musacchio, 2000; Vera, 1994). De acuerdo con la estadística oficial alemana, entre 1870-1914, los alemanes que emigraron hacia Chile fueron 9.859 y hacia Argentina 25.397 (Kellenbenz y Schneider, 1976; Musacchio, 2000).

Los alemanes en Chile tuvieron una profunda relación con tres ámbitos que el Estado fomentó durante el siglo XIX. Un primer factor fue una política de colonización hacia el extremo sur del país, a mediados del siglo XIX, lo que motivó una mayor incidencia estatal en territorios no ocupados y un fuerte desarrollo de asentamientos urbanos, como Valdivia, Osorno, Puerto Montt, simultáneamente con un desarrollo comercial de envergadura en la curtiembre, la ganadería, la industria cervecera (Blancpain, 1974; Guarda, 2011). Un segundo hecho a tener en cuenta fue la instalación de alemanes en ciudades importantes como Santiago, Valparaíso o Concepción, motivando el desarrollo mercantil de estas ciudades en distintos rubros y consolidando una emergente clase media en el país (Bernedo, 1999; Estrada, 2013; Salinas, 1992). Un tercer elemento, provino de su influencia educacional (Alarcón, 2014). Estos factores se verificaron hacia los últimos quince años del siglo XIX, en que se vivió lo que Blancpain (1974), Norambuena (2003) y Sanhueza (2010) han denominado el "embrujamiento alemán". Precisamente, a partir de esta influencia cultural que comienza en 1889 Chile, al decir de Rinke (1998), se "convirtió en una zona primordial de inversiones” (Rinke, 1998, p. 217), que se extendió hasta 1914. 
Fue en la segunda mitad del siglo XIX cuando los alemanes desenvolvieron una potente presencia en la región de Antofagasta, donde es factible comparar las inversiones establecidas en las ciudades del sur de Chile. Si Carlos Anwandter simbolizó el empuje de la emigración y la impronta empresarial en Valdivia (Blancpain, 1974), Carlos Pinnau se erigió como el paradigma del tesón y espíritu industrioso germano en Antofagasta.

También es dable acotar -en contraste con lo apreciado en el norte chileno- que la migración de los alemanes en la región de Los Lagos fue principalmente de artesanos urbanos y rurales y pequeños campesinos y fue promovida por el Estado chileno, a pesar de las reticencias de las iglesias luteranas y católicas alemanes. Blancpain refiere de la burguesía de Valdivia, los artesanos de Osorno y los colonos de Llanquihue (Bernedo, 1993; Blancpain, 1974; Ojeda, 1980).

Los alemanes de acuerdo a los censos nacionales de Chile, no se aproximaron hacia el desierto de Atacama, parte del territorio de la provincia de Atacama, de modo relevante, en contraste con el centro y extremo sur del país. De un total de 4.678 alemanes en el país, su distribución refuerza la acción de la política estatal de colonización del extremo sur, como podemos apreciar en la siguiente Tabla 1:

\section{TABLA 1}

Población alemana según Censo Jeneral de la Población de Chile de 1875.

\begin{tabular}{lllllc}
\hline $\begin{array}{l}\text { Provincia de } \\
\text { Atacama }\end{array}$ & 57 & $\begin{array}{l}\text { Provincia de } \\
\text { Coquimbo }\end{array}$ & 68 & $\begin{array}{l}\text { Provincia de } \\
\text { Aconcagua }\end{array}$ & 35 \\
\hline $\begin{array}{l}\text { Provincia de } \\
\text { Valparaíso }\end{array}$ & 1.163 & $\begin{array}{l}\text { Provincia de } \\
\text { Santiago }\end{array}$ & 298 & $\begin{array}{l}\text { Provincia de } \\
\text { Colchagua }\end{array}$ & 24 \\
\hline $\begin{array}{l}\text { Provincia de } \\
\text { Curicó }\end{array}$ & 13 & $\begin{array}{l}\text { Provincia de } \\
\text { Talca }\end{array}$ & 63 & $\begin{array}{l}\text { Provincia de } \\
\text { Linares }\end{array}$ & 17 \\
\hline $\begin{array}{l}\text { Provincia del } \\
\text { Maule }\end{array}$ & 30 & $\begin{array}{l}\text { Provincia de } \\
\text { Nuble }\end{array}$ & 72 & $\begin{array}{l}\text { Provincia de } \\
\text { Concepción }\end{array}$ & 351 \\
\hline $\begin{array}{l}\text { Provincia de } \\
\text { Bío-Bío }\end{array}$ & 138 & $\begin{array}{l}\text { Territorio de } \\
\text { colonización de } \\
\text { Angol }\end{array}$ & 26 & $\begin{array}{l}\text { Provincia de } \\
\text { Arauco }\end{array}$ & 108 \\
\hline
\end{tabular}




\begin{tabular}{lllll}
\hline $\begin{array}{l}\text { Provincia de } \\
\text { Valdivia }\end{array}$ & 729 & $\begin{array}{l}\text { Provincia de } \\
\text { Llanquihue }\end{array}$ & 1.156 & $\begin{array}{l}\text { Territorio de } \\
\text { colonización de } \\
\text { Magallanes }\end{array}$ \\
\hline
\end{tabular}

Fuente: Elaboración propia

Fuente: Quinto Censo jeneral de la población de Chile (Valparaíso, 1876)

No obstante, cuando se incorpora el desierto de Atacama y la ciudad de Antofagasta a la soberanía de Chile, como consecuencia de la Guerra del Pacífico (1879-1883), el balance demográfico en rasgos gruesos prosigue el delineamiento de 1875 para las provincias chilenas del extremo sur y las ciudades principales como Santiago, Valparaíso y Concepción. Si se verifica un cambio cuantitativo en Tarapacá y Antofagasta, que los censos nacionales incorporaron en 1885, pero con la salvedad que la cuantificación de extranjeros se realizó en el censo siguiente, el de 1895. Blancpain (1974) va a mencionar a Copiapó-La Serena, como el segundo ensayo alemán, ahora, en torno a los religiosos del Verbo Divino, al despuntar el siglo XX (Blancpain, 1974, p. 775).

Importante es poner de relieve que la presencia alemana en el desierto de Atacama responde a un contexto donde, por una parte se expande el capitalismo financiero y por otra, se tiene la formación de los imperios europeos, donde el alemán, después de la unificación alemana de 1870, comienza su penetración en ultramar hacia fines de la década de 1880 e inicios de 1890, mediante la ocupación de territorios físicamente -el modelo romano- o a través de su influencia en capitales y cultura -el modelo helénico-, paralelamente al despliegue de la globalización del liberalismo económico.

En el caso del desierto de Atacama -provincia de Antofagasta, desde 1888-, los alemanes competirán en influencia en todos los frentes con la influyente colonia inglesa durante todo el siglo XIX. 


\section{Política y negocios en el periodo anterior a la Guerra del Pacífico}

Después del proceso de poblamiento de La Chimba o Antofagasta, iniciado por Juan López en 1866 -fundada oficialmente por el gobierno de Bolivia en 1868- el desarrollo que experimenta el desierto de Atacama, con el comienzo de la explotación del nitrato por José Santos Ossa y el fundamental descubrimiento de la plata en Caracoles en 1870, los flujos migratorios hacia el territorio de la costa y del interior del desierto se acrecentaron.

Son años que discurren en el marco del Tratado de Límites entre Chile y Bolivia de 1866 y las modificaciones que se introdujeron en 1874, que afectaba la división de la frontera y los importes tributarios de los recursos explotados y las inversiones chilenas entre los paralelos 23 y 25.

En este marco, se desenvuelve una pugna soterrada entre la mayoría poblacional chilena, apoyada por las colonias europeas, y las autoridades bolivianas. El control de las instituciones fundamentales, desde el municipio, la junta de beneficencia hasta los bomberos, serán expresivos de la voluntad política en cuanto a la defensa de los intereses mineros y mercantiles, como de la fisonomía que se deseaba modelar a las nuevas ciudades (González, 2012). En tales finalidades, coincidentes entre la comunidad chilena y la alemana, se pudo observar la participación decidida de los integrantes germanos avecindados en Antofagasta. En cierta forma, el liderazgo de la colonia alemana fue asumido por Luis Lichtenstein: un destacado comerciante con inversiones en el rubro minero. Cuando se funda la Junta Municipal de Antofagasta, el 25 de enero de 1872, Luis Lichtenstein encabeza la contribución alemana, junto con Ernesto Wolcman, como concejil de la institución edilicia, compuesta de nueve miembros.

En gran medida, la visión europea reforzó la amplia labor ejercida por el municipio en cuanto al delineamiento del trazado urbano y la defensa institucional, de contar con amplias atribuciones edilicias en materias de contribuciones y terrenos fiscales (González, 2010). La otra institución fue la Junta de Beneficencia, creada en mayo de 1872, y que tuvo entre sus cinco primeros integrantes a Luis Lichtenstein. La Junta en 1875, amplió sus miembros y entre ellos estaban los alemanes Hugo Jenquel y 
Bernardo Eissmmann (Arce, 2004). El Cuerpo de Bomberos, fundado en abril de 1875, tuvo en la Compañía de Hachas, Ganchos y Escaleras como Capitán a Luis Lichtenstein.

El germen del sentimiento regionalista se confundió con un anhelo autonomista de los chilenos en el desierto. Este último se encauzó a través de la Sociedad de Socorros Mutuos "La Patria", que fue alentada por Juan Agustín Palazuelos, Salvador Reyes, Enrique Villegas y también por Luis Lichtenstein (Barros, 2015; González, 2005). Los objetivos de la organización, creada en Caracoles en octubre de 1876, los pudo recoger Benjamín Vicuña Mackenna: "Sus principales miembros, no desmayaban en la patriótica tarea que se habían impuesto, y sus trabajos y esfuerzos se concretaron a la Independencia del Litoral, cuya prosperidad y desarrollo se debía y se debe exclusivamente al trabajo de los chilenos" (Vicuña, 1880, p. 57).

La actuación de Lichtentein no pasó desapercibida para la representación consular chilena en Caracoles (Archivo Histórico del Ministerio de Relaciones Exteriores de Chile, Fondo Bolivia, vol. 39).

La expresión gráfica de la importancia comercial y financiera vinculada a capitales alemanes, se recoge en los planos citadinos de Antofagasta, los de José Santos Prada en 1869 (Panadés y González, 1998, p. 63) y el de Adolfo Palacios de 1873 (Bermúdez, 1966, p. 128), con la figuración del Banco Dorado y Wolkmar, las Máquinas de Neumann y Cía., Máquina de Lureling, Maestranza de Lureling y la Bodega de Lichtenstein.

En el Banco Nacional de Bolivia, fundado en 1870, participaron los alemanes Gustavo A. Hormann, Vice-Presidente, Guillermo Kruger, Secretario, Herman Fisher, Carlos von der Heyde, Consejeros (Arce, 2004).

La participación alemana en el campo del comercio se manifestó con muchos bríos en personas y capitales durante la década de 1870, que coincidió con el despegue de la industria salitrera de las dos áreas más importantes del desierto de Atacama: el cantón central bajo la administración boliviana y el cantón de Taltal bajo la jurisdicción chilena. A esto se sumó, un potente incentivo para el mercado del trabajo 
como para el incremento de las labores mercantiles, como fue el descubrimiento del yacimiento de plata de Caracoles, al despuntar 1870. En este conjunto de migrantes alemanes, sobresalió Carlos Pinnau que desde 1872 llevó sus mercaderías al mineral de Caracoles y fundó la Casa Pinnau. Posteriormente se unió a su compatriota Rodolfo Meyer abriendo el gran almacén de Meyer y Pinnau. Disuelta ésta, dio forma a la firma Pinnau y Cia, que siguió igual fortuna siendo reemplazada por la firma Pinnau. Otro alemán, Alberto Volgelstrom abrió una tienda para hombres bajo la razón social de "La Ropa Hecha".

El éxito de las actividades mercantiles movió a otros alemanes a tentar suerte en el desierto de Atacama. Es interesante apreciar la magnitud que alcanzó el rubro comercial operado por los alemanes en la ciudad de Antofagasta. Si nos aproximamos a lo que el historiador Isaac Arce denomina como la "segunda época de la fundación de Antofagasta", entre 1873-1878, podemos consignar un número significativo de alemanes, que se desenvolvieron en la actividad comercial como lo revelan los protocolos notariales de 1877-1878 (Tabla 2).

TABLA 2

Alemanes y el oficio de comerciante.

\begin{tabular}{lllll}
\hline NOMBRE & $\begin{array}{l}\text { NÚMERO DE } \\
\text { INSCRIPCIÓN }\end{array}$ & MESES- AÑO & LUGAR & RUBRO \\
\hline Luis Birchoff & 10 & $\begin{array}{l}\text { Enero/Febrero/ } \\
\text { Julio- } 1877\end{array}$ & Antofagasta & Comerciante \\
\hline Hugo de Voss & 1 & Enero-1877 & Antofagasta & Comerciante \\
\hline Luis Lichteintein & 1 & Febrero-1877 & Antofagasta & Comerciante \\
\hline Hugo Jenquel & 2 & $\begin{array}{l}\text { Marzo/Diciem- } \\
\text { bre-1877 }\end{array}$ & Antofagasta & Comerciante \\
\hline Jorge Schultze & 15 & $\begin{array}{l}\text { Marzo/Mayo/Ju- } \\
\text { lio/Septiembre/ } \\
\text { Noviembre-1877 }\end{array}$ & Antofagasta & Comerciante \\
& & Abril-1877 & Antofagasta & Comerciante \\
\hline Juan Radbruch & 1 & $\begin{array}{l}\text { Septiembre/Di- } \\
\text { ciembre-1877 }\end{array}$ & Antofagasta & Comerciante \\
\hline Rodolfo Meyer & 2 & & & \\
\hline
\end{tabular}




\begin{tabular}{lllll}
\hline Federico Koster & 1 & Octubre-1877 & Antofagasta & Comerciante \\
\hline Carlos Maier & 1 & Octubre-1877 & Antofagasta & Carpintero \\
\hline Emilio Leimbach & 1 & Noviembre-1877 & Antofagasta & Comerciante \\
\hline José Reszczynski & 2 & Diciembre-1877 & Antofagasta & Comerciante \\
\hline
\end{tabular}

Fuente: Elaboración propia

Fuente: Archivo Nacional de la Administración (Santiago de Chile): Notaría La Chimba, años 1877-1878.

El número de registro de inscripciones evidencia la frecuencia de sus operaciones mercantiles (desde la compraventa de bienes inmuebles, mutuo hipotecario, mandato, fianza, hasta la creación o disolución de sociedades). Cabe indicar que en este registro, la mayoría declara estar casado, con la excepción de Jorge Schultze y Carlos Maier.

Es importante hacer notar que el crecimiento de la población de Antofagasta, según el censo de la circunscripción municipal levantado el 10 de noviembre de 1878, arrojaba un total de 8.507 habitantes, donde la mayoría era de nacionalidad chilena, 6.554, seguida de la boliviana, 1.226, siendo la europea compuesta por 104 ingleses, 47 españoles, 40 franceses, 35 italianos, 32 alemanes, 23 austriacos (en su mayoría yugoslavos) (Hernández, 1930, p. 96).

Otros documentos de protocolos del bienio 1877-1878, provenientes de otras notarías, refuerzan la concentración de los germanos en el sector terciario de la economía, en consonancia con las grandes oportunidades de abastecimiento a una urbe en constante dinamismo y a la febril actividad minera de su hinterland que posibilita un explosivo surgimiento de nuevos campamentos hasta que la placilla de Caracoles se transforme en municipalidad (Tabla 3). 
TABLA 3

Comerciantes alemanes a fines del decenio de 1870.

\begin{tabular}{lllll}
\hline Rodolfo Meyer & 3 & $\begin{array}{l}\text { Marzo/Mayo } \\
\text { Julio-1878 } \\
*\end{array}$ & Antofagasta & Comerciante \\
& & & \\
\hline Emilio Leimbach & 1 & Junio-1878 & Antofagasta & Comerciante \\
& & $* *$ & & \\
\hline Godofredo Lagreze & 1 & Julio-1878 & Antofagasta & Comerciante \\
\hline Juan Radbruch & 1 & Julio-1878 & Antofagasta & Comerciante \\
\hline Juan Kuch & 1 & Septiembre-1878 & Antofagasta & Comerciante \\
\hline Gustavo Krushke & 2 & Septiembre/ & Antofagasta & Comerciante \\
& & Octubre-1878 & & \\
\hline Juan Radbruch & 1 & Octubre-1878 & Antofagasta & Comerciante \\
\hline Julio Keller & 1 & Octubre-1878 & Antofagasta & Comerciante \\
\hline Rodolfo Meyer & 1 & Noviembre-1878 & Antofagasta & Comerciante \\
\hline German Pinnau & 1 & Noviembre-1878 & Antofagasta & Comerciante \\
\hline Carlos Bauer & 1 & Noviembre-1878 & Antofagasta & Comerciante \\
\hline Emilio Leimbach & 1 & Noviembre-1878 & Antofagasta & Comerciante \\
\hline José Reszczynski & 1 & Diciembre-1878 & Antofagasta & Comerciante \\
\hline Enrique Döll & 2 & Diciembre-1878 & Antofagasta & Comerciante \\
\hline
\end{tabular}

Fuente: Elaboración propia

Fuentes: Archivo Nacional de la Administración (Santiago de Chile)

*Notaría La Chimba, 1878. Vol. 17.

**Notaría La Chimba, 1878. Vol. 18. 
Vinculado con esta primera expansión migratoria alemana, se debe visualizar la coincidencia con la llegada de los capitales. Un territorio periférico de la América del Sur lograba atraer un importante contingente demográfico, en consideración con el espacio y la cuantificación poblacional, donde encontramos a mineros interesados en las estacas salitreras del territorio chileno de Taltal. Hacia el sector de Aguas Blancas, el gobierno chileno, en conformidad al Reglamento sobre estacas salitreras de 28 de julio de 1877, otorgó las concesiones que se encontraban registradas en las notarías de Copiapó (Condición, 1892, p. XXIX). Figuraban entre los peticionarios Carlos Kahle, Federico Grote, Kahle y Grote, en diciembre de 1873; Juan Busch, en 1879, Benjamín Fischer, en 1880, Enrique Döll, en 1883, Luis Birchoff, en 1883, Luis Lichteintein, en 1883 (Folleto, 1905).

A esto hay que adicionar la información que consigna Roberto Hernández en el área de Aguas Blancas, donde en 1877 están en funcionamiento las oficinas Florencia, con 15 estacas, Esmeralda, con 64 estacas, Cerro del Árbol con 27 estacas, pertenecientes a Döll y Cía (Hernández, 1930, p.87). En Taltal, encontramos otro grupo de oficinas vinculadas con las inversiones germanas: la Sud-Americana, con 22 estacas, perteneciente a Jorge Berger; Chicoca con 5 estacas asociadas al nombre de Hugo Jenckel; Julia con 19 estacas a Weber y Cía.

Más al sur, en el cantón de Taltal, podemos ubicar un número importante de alemanes y descendientes de alemanes, que son peticionarios de estacas salitreras, entre los años 1876 y 1882, como Julio Barth, Alejandro Bruckner, Alfredo Brandt, Arturo Brencrofelth, Jorge Bischoffshausen, Otto Diefembach, Enrique Ehlers, Carlos Falck, Teodoro Finger, Alberto Falck, Teodoro Frademann, Enrique Haebler, Enrique Hintze, Jorge von Bischosfthausen, Eugenio von Wackhold Wherlhensträvich, Enrique Haberman, Roberto Hasman, I. Haltenhof, Enrique Jenkin, Eduardo Kelplsell, Kristian Köning, Carlos Klinchsmidt, Emilio Krüger, Joaquín Knaupp, Julio Kaulen, Jorge Lhenemann, Luis Pacht, Juan Rodbwik, Jorge Ranemberg, Gustavo Rosenberg, Pedro Scholjberg, Tomás Seeppelkow, Federico Steimbarth, P.Ambrosio Schyllcke, Augusto Thielban, Julio Schaffer, Andrés Stambuch, Federico Slhmer, Otto Seeger, Pablo Stocker, Juan Stuven, Carlos Schoder, Emilio Scheffer, y los conocidos Jorge Hilliger y Hugo Jenequel (Indice, 1905). 
De acuerdo con Carlos Aldunate Solar, los Döll y Cía, adquirieron de la Sociedad Emeterio Moreno y Cia, las oficinas Esmeralda -en mayo de 1882- y Central en julio de 1883 (Citado por Hernández, 1930, p. 156). Aquello significó otro impulso para las actividades comerciales de abastecimiento a las oficinas salitreras de Aguas Blancas, desde la base de operaciones de Antofagasta.

\section{La consolidación del poderío comercial alemán en la ciudad de Antofagasta, entre 1880-1900}

¿Cómo explicar, ahora, los factores exógenos que van a facilitar esta migración? Determinados autores (Bértola y Ocampo, 2013; Marichal, 2011) han planteado para el periodo temporal que nos interesa, entre 1870-1900, que se dieron cita tres factores relevantes. Uno de ellos fue el incremento del comercio internacional, otro el aumento de los flujos de capitales y, por último, el alza de las migraciones masivas del tipo intercontinental ${ }^{1}$ (Gould, 1979; Taylor y Williamson, 1994). En las naciones latinoamericanas, los rasgos de esta globalización convergieron con los cambios político-institucionales derivados de las reformas económicas liberales junto con la consolidación de las estructuras de poder político.

En general, la migración libre que se verificó entre 1880 hasta el fin de la Primera Guerra Mundial, produjo consecuencias contradictorias: por un lado, como ha enfatizado O'Rourke (2004), constituyó un camino efectivo en los países pobres para mejorar el estándar de vida, un proceso autolimitado, y produjo efecto en la distribución interna de los ingresos, del país de origen como en el país receptor y, por otro, el factor inmigratorio tendió a reducir los salarios reales en los países receptores y a realizarse, a veces, de modo conjunto que el flujo migratorio fuese acompañado con la llegada de capitales en las nuevas tierras (Hatton y Williamson, 2006). Esto se verifica en la migración de británicos y alemanes. En estos últimos, los registros notariales refieren de esta acumulación de capitales inicial acrecentado con la pujanza y éxito comercial en el desierto.

Se identifica con este término a la emigración desde Europa a América, especialmente destinada a localizarse, entre otros, en Estados Unidos, Brasil y Argentina. 
La política chilena de la época fue claramente influenciada por el liberalismo económico. En el espacio del norte salitrero impulsó los trenes privados, la creación de los muelles de empresas y los fiscales; en general, la actividad económica fue proclive a la iniciativa privada con mínimas intervenciones estatales. Esto se verificó con el tránsito de forasteros, viajeros y los flujos de migrantes hasta el año 1906 cuando por razones políticas -la sospecha de elementos anarquistas europeos- se firmó el convenio policial de Buenos Aires para el registro de extranjeros.

Un antecedente importante fue el hecho que la colonia alemana conjuntamente con la británica, a diferencia de otras colonias europeas, como la española, la italiana, la yugoslava o la griega, no formó sociedades de socorros mutuos o de beneficencia para apoyarse recíprocamente. Una situación distinta fue la que se observó en el sur, "Club Obrero Teutonia" o la "Liga de Sociedades Obreras" de Valparaíso, refiere Blancpain (1974, p. 823). En la segunda fase de la migración alemana, señala el historiador francés, entre 1882 y 1890, se encuentra una composición de trabajadores agrícolas y proletarios, lo cual indica cierto componente de migrantes pobres (Harris, 1997). Etapa que en Antofagasta, otros migrantes europeos procuran el auxilio étnico. La Sociedad de Beneficencia Italiana, fue creada en julio de 1893, al año siguiente, se fundó la Sociedad Yugoslava de Socorro Mutuo; en 1895, vio luz la Sociedad Española de Beneficencia, en 1916 la Sociedad Helénica de Socorros Mutuos (Arce, 2004, p. 344-345).

Si nos aproximamos a las últimas décadas del siglo XIX, cuando se impuso la hegemonía de la explotación salitrera sobre las labores argentíferas del mineral de Caracoles, podemos constatar de qué manera la adquisición de propiedades, la formación de sociedades, el establecimiento de entidades financieras, acrecentó la presencia alemana en la ciudad de Antofagasta. Para ello, nos sirve la cuantificación recogida en la documentación del Conservador de Bienes Raíces del periodo 1880-1890 como el Registro de Avalúos de 1894. Ambas posibilitan visualizar las concentraciones comerciales en un núcleo de grandes comerciantes que hemos observado en el periodo fundacional, como los hermanos Döll, Pinnau, Koster, y su localización en las áreas de mayor plusvalía urbana. 
TABLA 4

Movimiento mercantil alemán entre 1880-1890.

\begin{tabular}{|c|c|c|c|c|}
\hline CONSERVADOR & BIENES & RAICES: & PROPIEDADES & \\
\hline AÑO & VOL. & INSCRIP. & NOMBRE & CAUSA \\
\hline 1880 & 7 & 51 & Doll y Cía. & $\begin{array}{l}\text { Compraventa } \\
\text { propiedad calle } \\
\text { Caracoles c/Lamar }\end{array}$ \\
\hline 1880 & 7 & 52 & Doll. y Cía. & $\begin{array}{l}\text { Adjudicación } \\
\text { terreno calle Sucre }\end{array}$ \\
\hline 1880 & 7 & 54 & Doll. y Cía. & $\begin{array}{l}\text { Compraventa } \\
\text { prop.en } \\
\text { Antofagasta }\end{array}$ \\
\hline 1880 & 7 & 66 & Federico Koster & $\begin{array}{l}\text { Compraventa } \\
\text { prop. Calle } \\
\text { Washington c/ } \\
\text { Sucre }\end{array}$ \\
\hline CONSERVADOR & BIENES & RAICES: & HIPOTECAS Y & GRAVÁMENES \\
\hline 1880 & 7 & 26 & Doll y Cía & $\begin{array}{l}\text { Acreedor en } \\
\text { hipoteca prop. } \\
\text { calle Sucre }\end{array}$ \\
\hline CONSERVADOR & BIENES & RAICES: & COMERCIO & \\
\hline 1881 & 10 & 6 & Doll y Cía. & $\begin{array}{l}\text { Mandato para } \\
\text { Luis Birchoff } \\
\text { para ciudad de } \\
\text { Antofagasta }\end{array}$ \\
\hline 1881 & 10 & 9 & Doll y Cía & $\begin{array}{l}\text { Mandato a Luis } \\
\text { Birchoff }\end{array}$ \\
\hline CONSERVADOR & BIENES & RAICES: & PROPIEDADES & \\
\hline 1881 & 10 & 5 & Juan Radbruch & $\begin{array}{l}\text { Edifica prop.en } \\
\text { terreno fiscal de } \\
\text { calle Condell }\end{array}$ \\
\hline CONSERVADOR & BIENES & RAICES: & COMERCIO & \\
\hline
\end{tabular}




\begin{tabular}{|c|c|c|c|c|}
\hline 1882 & 13 & 1 & Carlos Bauer & $\begin{array}{l}\text { Soc. c/ Juan } \\
\text { Barnett: } \\
\text { Establecimiento } \\
\text { de Fundición } \\
\text { Bellavista }\end{array}$ \\
\hline 1882 & 13 & 2 & Luis Birchoff & $\begin{array}{l}\text { Soc.c/ Laureano } \\
\text { Oyanadel: } \\
\text { Oyanadel y } \\
\text { Cía: embarco y } \\
\text { desembarco de } \\
\text { mercaderías }\end{array}$ \\
\hline 1882 & 13 & 2 & Federico Koster & Ibid. \\
\hline 1882 & 13 & 9 & Carlos Bauer & Ibid. \\
\hline 1882 & 13 & 9 & Federico Koster & Ibid. \\
\hline 1882 & 13 & 9 & Doll y Cía. & Ibid. \\
\hline 1882 & 13 & 6 & Carlos Bauer & Ibid \\
\hline CONSERVADOR & BIENES & RAICES: & REGISTRO DE & COMERCIO \\
\hline 1883 & 17 & 3 & Juan Werner & $\begin{array}{l}\text { Soc.c/ Jorge } \\
\text { Kinderman: } \\
\text { compra y venta } \\
\text { de licores y } \\
\text { mercaderías }\end{array}$ \\
\hline 1883 & 17 & 7 & Juan Werner & $\begin{array}{l}\text { Disolución } \\
\text { sociedad Werner } \\
\text { y Cía. }\end{array}$ \\
\hline CONSERVADOR & BIENES & RAICES: & PROPIEDADES & \\
\hline 1884 & 21 & 19 & Federico Koster & $\begin{array}{l}\text { Compraventa } \\
\text { prop.calle } \\
\text { Baquedano }\end{array}$ \\
\hline 1884 & 21 & 45 & Federico Koster & $\begin{array}{l}\text { Adquiere prop. } \\
\text { calle Prat }\end{array}$ \\
\hline 1885 & 25 & 54 & Doll y Cía & $\begin{array}{l}\text { Compraventa } \\
\text { prop.calle Sure }\end{array}$ \\
\hline 1885 & 25 & 59 & Doll y Cía & $\begin{array}{l}\text { Compraventa } \\
\text { prop.calle Sucre }\end{array}$ \\
\hline CONSERVADOR & BIENES & RAICES: & COMERCIO & \\
\hline
\end{tabular}




\begin{tabular}{|c|c|c|c|c|}
\hline 1887 & 33 & 15 & $\begin{array}{l}\text { Roberto } \\
\text { Brunswig }\end{array}$ & $\begin{array}{l}\text { Sociedad } \\
\text { Francisco Páez: } \\
\text { Botica Brunswig } \\
\text { y Cía. }\end{array}$ \\
\hline CONSERVADOR & BIENES & RAÍCES: & HIPOTECAS Y & GRAVAMENES \\
\hline 1888 & 37 & 58 & Augusto Pinnau & $\begin{array}{l}\text { Mutuo hipoteca } \\
\text { prop. cerca Plaza } \\
\text { Colón favor } \\
\text { Banco Valparaíso }\end{array}$ \\
\hline CONSERVADOR & BIENES & RAICES: & PROHIBICIÓN E & INTERDICCIÓN \\
\hline 1888 & 37 & 1 & Francisco Meyer & $\begin{array}{l}\text { Prohibición } \\
\text { inscribir títulos } \\
\text { ubicados en } \\
\text { Antofagasta }\end{array}$ \\
\hline CONSERVADOR & BIENES & RAICES: & PROPIEDAD & \\
\hline 1890 & 46 & 11 & Carlos Pinnau & $\begin{array}{l}\text { Venta de su } \\
\text { establecimiento } \\
\text { para el espendio } \\
\text { de agua en Sierra } \\
\text { Gorda }\end{array}$ \\
\hline 1890 & 46 & 32 & Daniel Berger & $\begin{array}{l}\text { Venta de un sitio } \\
\text { en Calama }\end{array}$ \\
\hline CONSERVADOR & BIENES & RAICES: & COMERCIO & \\
\hline 1890 & 46 & 1 & $\begin{array}{l}\text { Alejandro } \\
\text { Vischer y Cía. }\end{array}$ & $\begin{array}{l}\text { Prórroga sociedad } \\
\text { por un año }\end{array}$ \\
\hline 1890 & 46 & 6 & Meyer y Pinnau & $\begin{array}{l}\text { Disolución } \\
\text { sociedad }\end{array}$ \\
\hline 1890 & 46 & 7 & Rodolfo Meyer & $\begin{array}{l}\text { Sociedad con } \\
\text { Carlos Pinnau: } \\
\text { compra y venta } \\
\text { mercaderías }\end{array}$ \\
\hline 1890 & 46 & 8 & $\begin{array}{l}\text { Establecimiento } \\
\text { Fundición } \\
\text { Bellavista }\end{array}$ & $\begin{array}{l}\text { Reforma razón } \\
\text { social: Cía. De } \\
\text { Fundición y } \\
\text { Beneficiadora de } \\
\text { Antofagasta }\end{array}$ \\
\hline
\end{tabular}




\begin{tabular}{lllll}
\hline CONSERVADOR & BIENES & RAICES: & PROPIEDAD & $\begin{array}{l}\text { CONSERVADOR } \\
\text { DE MINAS }\end{array}$ \\
\hline 1890 & & & & Vende a Enrique \\
& 46 & 5 & José Ponzini & Doll el $15 \%$ \\
& & & yacimiento de \\
& & & sulfato de cal "La \\
& & & Yecera", ubicada \\
& & & al norte de \\
& & & Antofagasta. \\
& & &
\end{tabular}

Fuente: Elaboración propia

Fuente: Archivo Nacional de la Administración (Santiago de Chile). Conservador de Bienes Raíces de Antofagasta, Años 1880-1890.

Al incremento de establecimientos comerciales, se sumaba una ocupación del espacio urbano tanto en áreas consolidadas, como el centro, como en zonas de ampliación en dirección sur-poniente. Apreciar la localización de las casas comerciales de los alemanes no sólo implica la estrategia de casas comerciales mayoristas por abarcar más clientes y copar mercados emergentes, por medio de la instalación de almacenes, nuevos despachos y bodegas, sino también hacer patente la gravitación individual al interior de una colonia y su incidencia en el rumbo comercial de la ciudad de Antofagasta. Y esto lo podemos verificar en la expansión de casas emblemáticas de apellidos alemanes de la etapa fundacional de la urbe en distintas arterias de Antofagasta. Así se constata el florecimiento de la Casa Meyer Pinnau, que reconocía dependencias en calles 14 de Febrero números 149 y 151, calle Independencia números 35 y 39, calle Angamos 57 y 61, calle Latorre y Sucre, calle Prat 164, calle 14 de Febrero números 35 y 37 (Mandiola y Castillo, 1894, p. 55-88). Asimismo, P. M. v. de Pinnau indicaba calle 14 de Febrero números 39 y 43 y A. Pinnau, calle San Martín número 128. Ciudadanos germanos como los hermanos Döll, Fernando y Enrique, se establecieron con una firma comercial en la urbe expandiendo sus negocios hacia la pampa salitrera. Los Döll y Cía, poseían inmuebles en calle Latorre número 167, en San Martin sin número, en Orella con 21 de Mayo, en calle Condell sin número, en San Martín con Prat, en Sucre número 20 y en la esquina de calle Independencia y Colón número 62. Enrique Döll figuraba con inmuebles en calle Prat números 82 y 84 y en calle Condell 132 y 134 . Otros alemanes sobresalieron 
en este rubro. Uno de ellos fue Gustavo Krumsick que tenía almacenes en Latorre sin número, Maipú número 56, en Condell sin número y en calle Washington sin número. Pedro Tensich estaba en calle San Martín 115. Federico Köster poseía tiendas en Sucre números 9 y 12, Baquedano números 103 y 107 y en calle Latorre número 251. A. Francke y Cía. comerciaba en calle San Martin números 72 y 76. D. Schubering y Cía, se encontraba en calle Washington sin número (Arce, 2004, p. 124-127). Otros alemanes que sobresalieron fueron Juan y Carlos Radbruch, en el rubro de Agentes de Aduana y Comisionistas, Emilio Leimbach, Juan Kul, Enrique Schiligting (a veces figura como Shiligting), Teodoro Bunger, Carlos Waschman, Pedro Hansen, Bernardo Eissmmann, Guillermo Muller.

En la última década de 1890, prosiguen las actividades comerciales de los alemanes más sobresalientes en el rubro, como los Pinnau, y se incorporan en gestiones notariales -verdadero barómetro de la fluidez y densidad en el ámbito comercial- otros nombres que, en su mayoría se adscriben al oficio de comerciante, Isaac Lang (Notaría, 1891, Vol. 48, Inscripción 17), Luis Stuven, Carlos Bauer, Agustin Pommer, Juan Henssen, Walterio Burckhardt, Carlos Pinnau, Guillermo Hartel, Carlos Manstein, Gustavo Krumsiek, Mauricio Wertheim, Luis Schonfeldt (Notaría, 1897, Vol. 85, Inscripciones 27, 197, 198, 240, 255, 289, 294, 419, 455, 476, 760). También ese año, 1897, figuran en el rubro comercial, Frank Segundo Maechel, Fernando Krumm, Alberto Stuven, Pablo Kholer, Gustavo Bubeck, Marcos Flich, Mauricio Wartheim, Otto Witte, Ludwig Kloz, Ricardo Schubering, Rodolfo Guggisberg, Guillermo Rees, Augusto Schimmer, Juan Scherzer, Andreas Kundsen, Guillermo Letcher, Luis Schonfeldt, Carlos Lohmann, German Berger, Elard Darelsberg, Eduardo Knandt, Otto Reszczynky (Notaría, 1897, Vol.88, Inscripciones 1, 45, 74, 81, 130, 145, 205, 232, 240, 257, 268, 281, 430, 505, 609, 662, 721, 740, 757, 752, 735), Gustavo Visscher, Germán Beredsen, Alfredo Schatzmann, Alejandro Visscher, Gustavo Krumsiek, Gustavo Oheringer, Carlos Baur, Federico Bubek, Walter Gower, Julio Martens, Rodolfo Bohl, Guillermo Hortel, Rodolfo Schartge, Luis Kerbernhard, Alfonso Deppe, Franz Germann, Alberto Deppe, Enrique Wolffing, Walter Lihn, Eduardo Bayer, Adolfo Schwartze, Luis Dumm, Luis Kerberhard, Juan Beck, Jeromen Prasch, Roberto Mathaes, Rosa Schmidt, Juan Henssen, Sofía de Visscher Avell, Carlos Brieger, Rodolfo Schiocertze, Alfredo Burger, Jorge Bosche, Doimo Reich (Notaría, 1896, Vol.79, Inscripciones 47, 51, 74, 101, 171, 199, 205, 216, 217 , 220, 229, 233, 236, 237, 250, 257, 258, 349,424, 428, 442, 450, 486, 498, 511, 517, 
$533,535,574,591,659,683)$.

En el año 1898, a la vigencia de los Pinnau, Scherzer, Schubering, Stuven, Krumsick, se añaden los nombres de Luis Stuven, Luis Schonfeldt, Mauricio Wertheim, Walker Lihn, Carlos Malmstein, Juan Henssen, Carlos Marschhansen (Notaría, 1899, Vol. 96, Inscripciones 25, 17, 100, 229, 235, 255, 289, 304), Roberto Brunswig, Ricardo Schubering (Notaría, 1899, Vol. 97, Inscripciones 705, 812), Benjamín Fisher, Ricardo Schubering, Juan Gohring, Roberto Brunswig, Gustavo Federico Bubek, Juan Scherzer, Federico Duhn, Mauricio Wertham (Notaría, 1899, Vol.99, Inscripciones 10, 11, 23, 46, 48-52, 84-85, 101, 258). Durante el año, se repiten varios de los apellidos: los hermanos Asmussen, Federico y $\mathrm{Julio}^{2}$, Schubering, Hansen, Brunswig, Schonfeldt, y se incorporan otros como Carlos Eissmann, Samuel Hoffmann, Federico Kommert, Alberto Reinhardt, Luis Kerbornhard, Rodolfo Hoffman, Augusto Stumpf (Notaría, 1899, Vol. 99, Inscripciones 427, 607, 622, 688, $852,1007,1011)$.

Este crecimiento del flujo migratorio alemán en el último decenio del siglo XIX, tiene relación, especialmente en el sector comercial, con el arribo de los capitales alemanes a la industria salitrera. Son inversiones que provienen de la experiencia salitrera de Tarapacá. Guillermo Billinghurst, al referirse a las casas industriales de Gildemeister y Folsch y Martin, ponderó que

han alcanzado el grado de prosperidad en que actualmente se encuentran porque han tenido el tino de confiar la administración de sus oficinas a personas competentes a quienes han interesado de una manera permanente en el éxito de sus explotaciones salitreras (Billinghurst, 1889, p. 104; Bermúdez, 1966).

Henry B. Sloman trabajó en Tarapacá con Jorge Hilliger y posteriormente se desenvolvió en la Compañía de Folsch y Martin, por espacio de 22 años, volviéndose autónomo y trasladándose hacia la provincia de Antofagasta, al despuntar 1890.

2 Los Asmussen que llegan a la ciudad, de ascendencia alemana, se vinculan con la colonización germana de mediados del siglo XIX, y no figuran en los prontuarios de extranjería por lo que más que probable hayan sido una tercera generación. 
Los nombres de Herman Conrad Folsch y Henry Brarens Sloman, son los prohombres del capitalismo alemán surgido al tenor de las empresas salitreras tarapaqueñas en torno a Gildemeister. Desde 1890 las inversiones germanas se localizan en el cantón de Taltal, principalmente Folsch y Martin, y en el cantón del Toco, en la jurisdicción comunal de Tocopilla, las de Sloman, que logra levantar cuatro oficinas "Buena Esperanza", "Grutas", "Empresas Buenaventura" y el famoso Tranque Sloman (Blancpain, 1974, p. 809-810).

Resulta llamativa -en estos veinte años- la confluencia de los intereses empresariales en el periodo entre alemanes y británicos que se manifiesta en distintos órdenes. Federico Koster compra una propiedad al inglés Hugo Stevenson, en 1880 (Conservador, 1880, Vol.7, Inscripción 66), Carlos Baur se une con el inglés Juan Barnett, para trabajar el importante establecimiento de Fundición Bellavista, en 1882, para transformarlo en la Compañía de Fundición y Beneficiadora de Antofagasta, en 1890, según consta en el Conservador de Bienes Raíces. El alemán Walker Rohl se asociará con el inglés Norman Walker para fundar "Walker Rohl y Cía", en mayo de 1898. Walker otorgará mandato al alemán Gustavo Rubeck, en ese mes y año. Rubeck en reciprocidad le entrega mandato a Walker, para que lo represente en Tacna, y después un mandato especial, en enero de 1899. Luis Schonfeldt le compra una propiedad a Walker, en abril de 1899. Lo mismo hace Mauricio Wertheim con Walker, en julio de 1899. El alemán Juan Henssen otorga mandato a Perkins Shanks, en septiembre de 1898. Este último hace lo mismo en la persona del alemán Ricardo Schubering, en enero de 1899. Roberto Rees le compra una propiedad al inglés Jorge Barnett, en diciembre de 1899. También hubo vinculación entre Federico Asmussen con el inglés Santiago Bennet, en junio de 1899. El alemán Juan Scherzer, ejerció como Administrador del Ferrocarril de Antofagasta y representó a la Compañía Huanchaca de Bolivia, durante el año 1898 (Notaría, 1898, Vol. 93, Inscripciones $44,366,455)$.

La visibilidad de la presencia alemana en la urbe, no solo se manifestó en la cantidad de casas comerciales, almacenes, bancos, bodegas, sino con sus servicios fotográficos, que estaba en total sintonía con el desarrollo tecnológico y visual de la Revolución Industrial. Rodríguez Villegas indica que hacia 1880 estaba la Fotografía Alemana de Augusto Reiken (Rodríguez, 2001, p. 69) y hacia 1882, otra (o la misma) 
Fotografía Alemana de Enrique Dohrn y Cía. (Rodríguez, 2001). Luego estuvieron los hermanos Lassen, quienes habían trabajado en Cochabamba y que se instalaron en Antofagasta antes de 1894 (Mandiola y Castillo, 1894). Los aportes alemanes a los estudios fotográficos, importantes por la difusión de las primeras postales citadinas y de la febril actividad portuaria, se vio reforzada por la llegada desde Hamburgo, en 1895, del fotógrafo profesional Alberto Benque (Rodríguez, 2001).

Los alemanes además destacaron en el rubro químico farmaceútico. La Guía de Antofagasta de 1894 publicitaba la Droguería y Botica Alemana de Roberto Brunswig que quedaba en calle Latorre 149 y 151, entre Uribe y Orella, con sucursal en las esquinas de las calles Prat y Latorre (Mandiola y Castillo, 1894). Agustín Pommer era propietario de una Botica y Droguería en calle Prat 136 y 138. Por otro lado, Alejandro Visscher y Cía. eran agentes de aduana, G. Krumsieck era agente, consignatario y comisionista, además era agente de la línea de vapores HamburgPacific (Mandiola y Castillo, 1894).

Las redes comerciales entre alemanes fueron muy estrechas, confundiéndose a veces las vinculaciones parentales con las económicas. La familia Döll, por medio de Elisa, se vinculó con los Lihn, al desposarse con Walter Lihn. Clara Reszczynski fue cónyuge de Luis Schonfeldt, hermana de Otto.

La expansión alemana también se vio reflejada a partir del censo nacional de 1895 en su importancia demográfica en la región de Antofagasta, como se muestra en la Tabla 5.

\section{TABLA 5}

Importancia relativa de población extranjera migrante y la alemana. Censo de 1895.

\begin{tabular}{lll}
\hline Provincia & Hombres & Mujeres \\
\hline Total Población Prov. de Antofagasta & 26.039 & 18.046 \\
\hline Total Población extranjera Prov. De Antofagasta & 4.049 & 2.141 \\
\hline $\begin{array}{l}\text { Población extranjera como \% Población Total de Prov. } \\
\text { de Antofagasta }\end{array}$ & $15.5 \%$ & $11.9 \%$ \\
\hline
\end{tabular}


Total Población Extranjera como \% Población Total en $3.9 \% \quad 5.7 \%$ Chile

\begin{tabular}{lll}
\hline Total Población alemana Prov. De Antofagasta & 172 & 22 \\
\hline Alemanes como \% Población Extranjera Total en Prov. & $4.2 \%$ & $1.0 \%$ \\
De Antofagasta & & \\
\hline
\end{tabular}

Fuente: Elaboración propia

El censo de 1895 registraba el mismo panorama demográfico espacial de la colonia alemana a nivel nacional, aunque se percibe una disminución del proyecto colonizador en el extremo sur. Las provincias salitreras de Tarapacá y de Antofagasta se integran entre las zonas que concentran una población alemana significativa, como lo hace constar el censo en cuestión (Tabla 6).

TABLA 6

Provincias que concentran mayor población alemana.

\begin{tabular}{llll}
\hline Provincia de Tarapacá & 417 & Provincia de Antofagasta & 194 \\
\hline Provincia de Santiago & 1.069 & Provincia de Valparaíso & 1.478 \\
\hline Provincia de Concepción & 556 & Provincia de Arauco & 129 \\
\hline Provincia de Bío-Bío & 132 & Provincia de Malleco & 309 \\
\hline Provincia de Cautín & 342 & Provincia de Valdivia & 946 \\
\hline Provincia de Llanquihue & 845 & Provincia de Magallanes & 120 \\
\hline
\end{tabular}

Fuente: Elaboración propia

Fuente: Oficina Central de Estadística, Sétimo censo jeneral de la población de Chile levantado el 28 de noviembre de 1895 (1900, I: p. 63, 155, 125;1902, II: p.322; 1903, III: p.418, 511, 652;1904, IV: p.95, 148, 210, 300, 430).

\section{Las redes sociales alemanas: inserción en la sociedad regional y capital social}

Es interesante anotar, que los alemanes que arribaron al desierto de Atacama vía marítima, pudieron establecer redes sociales rápidamente, fuese por motivos comerciales, por razones de conocer a otros connacionales o vincularse con chilenos 
en dicha área, lo que, en definitiva, les permitió reafirmar su decisión de asentarse en el territorio.

Cuando se levantó el registro de extranjería por parte de la policía, a partir del convenio policial suscrito en Buenos Aires en 1906 (Convenio, 1906), se pudo contar con una información personal muy relevante. ${ }^{3}$

Así sabemos que entre los primeros alemanes que arribaron a la ciudad de Antofagasta figuraron Enrique Hering Lube, procedente de Westfalia, llegó a Chile en 1870, de oficio maestro panadero, alfabetizado, casado con Celvide Torre ${ }^{4}$; ese mismo año de 1870 declara haber arribado Katherine Veilth Beig, desde Wurtemberg, que sabe leer y escribir y está dedicada a labores doméstica, al momento de su afiliación por la policía se encuentra viuda. Entre sus relaciones señala a Elizabeth M. de Pinnau y a Marie E. Thomas (31/16842). Federico Ensemeyer Luza, que el documento no consigna su lugar de procedencia, pero que llegó en 1872, sabe leer y escribir, es soltero y empleado al momento de registrarse (31/14169), mientras su hermano Carlos, que llegó en 1874, está viudo- al momento de confeccionarse su prontuario- y se desenvuelve como empleado (31/14170). Luis Lühr Buchholz, vino desde Hannover, en 1875, casado con Gertrudis Nichell, de oficio talabartero (33/16672). Dos años antes, había arribado a Antofagasta Carlos Pinnau Bründel, nacido el 5 de mayo de 1849 en Hamburgo, lugar desde donde se traslada hacia el desierto de Atacama. Estaba casado con Elizabeth Berth (34/12697). En el año 1879, procedente desde Magdeberg, llega David Schwartz Schubart, comerciante, quien se casa con Dominga Arqueros (35/16974). En 1880 desde Damberg, llega el ingeniero Federico Roth Handtmann, casado con Dorotea Knabe, que declara como relaciones a Carlos Pinnau y a Otto Kutz, ambos comerciantes (34/1901). En 1882 llega Alejandro Visscher, casado con María Damelberg, dedicado al comercio

3 El Prontuario - -llevado a cabo por la Policía de Antofagasta, Sección de Identificación- estaba conformado de ocho páginas. La página 1 estaba destinada al registro de tres fotografías (que comúnmente no se anexaba); la página 2 a la Filiación, desde su procedencia geográfica hasta las señas de sus padres; la página 3 las Señas Particulares, Parientes o relaciones sociales; las páginas 4, 5 para las Observaciones: Características Cromáticas ; página 6 a las Características descriptivas analizadas de perfil; contorno general y de frente; la página 7 registraba las huellas dactilares tanto y la página 8 para Observaciones.

4 Archivo Histórico de la Universidad Católica del Norte: Archivo de Extranjería del Registro Civil e Identificaciones, Alemania, Cajas 31-36. Citaremos en el texto en primer lugar la caja y seguidamente el número del prontuario. 
(31/45116) y Carlos Werner Stange, soltero, de oficio peluquero, que refiere sus relaciones con Martin Grandi, comerciante, y Guillermo Kunsemuller (36/5841). Enrique Oschilewisky Melcher, provino desde Berlín en 1883. Se casó con María Luisa Concha y se dedicó al ejercicio de mecánico (34/24610). Al año siguiente encontramos a Gorsfried Schadewitz Kohler, soltero, contador, que declara como relaciones a Jorge Levy (35/16890). En 1884 encontramos en Antofagasta a Willi Kutz Schablansky, berlinés, casado, comerciante que señala como relaciones a Carlos Pabst, comerciante de calle Orella 617 y a Ricardo Blermayer, comerciante de calle Uribe 617 (33/80058). También ese año llega Otto Kutz Uthe, oriundo de Bernburg, casado con Berta Chabinfski, comerciante. Entre sus nexos en la ciudad refiere a Federico Roth, ingeniero, domiciliado en calle Angamos 79, y a Enrique Koetschan, empleado, con residencia en calle Prat 840 (33/1902). Con ellos llega también Martín Schusler Kock, desde Sajonia, soltero, comerciante, que menciona como conocidos a Carlos Pfeiffer, ingeniero en la Compañía de Cervecerías Unidas, y a Juan Grane, comerciante de calle Prat 1142 (35/46713). También se hace presente Henriette Herforth Heinemann, comerciante, viuda de Máximo Elbo (32/44633). En 1885, arriba Pedro Michaelson Tribiar, desde Hamburgo, de profesión ingeniero civil, casado con Elizabeth Koch, cuyas relaciones son Ricardo Ayala, Gerente de la Compañía de Salitres de Antofagasta y Alfredo Campaña, Administrador de la Compañía de Salitres de Antofagasta (33/51553). Al año siguiente, se hace presente desde Halle, Arturo Wehuhaln Mazuck, de profesión dentista, quien se casa con Mercedes Gaviño. Indica como relaciones a Carlos Pabst y a Otto Kutz (36/17321). Ese año de 1886, llega Antonio Lassen Eber, soltero, comerciante y Carlos Hortmann, que señala ser práctico, casado $(33 / 9829 ; 32 / 691)$. Al año siguiente, Roberto Nathu Karger, casado, que señala ser naviero, y también Erick Gluimann Oberdick, comerciante, casado con Elizabeth Haenderlen (31/12944). En 1888 procedente desde Hamburgo, arriba Augusto Donnet Misler, casado, de profesión ingeniero, quien da las referencias de Guillermo Pinnau y de Carlos de la Fuente (31/8786). En la década de 1890 arribaron, en 1890 Hermann Wachter Seiffert, desde Leipzig, soltero, mecánico (36/19492); en 1891 Carlos Macker Walter, desde Frankfurt, comerciante, casado con Zaila Ganderattz (33/13247); al año siguiente, Bruno Humbser Rainbaord, desde Hamburgo, casado, empleado (32/19001); en 1893 Bonin Pett Galiand, berlinés, ingeniero de minas, y Ernest Bernardij Lecher, desde Hamburgo, soltero y comerciante (34/108473; 30/86229); en 1894 Carlos Pabst Stein, joyero, casado con María Pabst, y Antonio Weipperts Hunter, soltero, empleado (34/2493; 
36/42770). Al año siguiente, llega Carlos Heubel Wübbe, soltero, comerciante, que refiere conocer a Guillermo Kümuller, farmaceútico, de la Botica Alemania de calle Prat, a Otto Hernig, comerciante, de la misma calle, y a Dimitri Tacussi, contador, de calle Condell 968 (32/47439). En 1896, llega el mecánico Fritz Rathje Meyer, que se casará con Lazxenia Díaz, y Dora Waisan Erichsen, desde Kiel, profesora, que da las referencias de Elizabeth Pinnau (34/2563; 36/16470). En 1898 arriba Joaquín Schmidt Gluding, soltero que se declara comerciante, Enrique Kötsechan Solbig, desde Hamburgo, soltero y comerciante, que da como referencias a Carlos Pabst y Ricardo Blermayer, ambos comerciantes, y finalmente también desde Hamburgo Pablo Frey Ziegelstorff, casado, empleado, que da la referencia de Carlos Pabst (35/6648; 33/2081; 31/197). Ese año también encontramos a Elena Vicke Peyadz, que al momento de su filiación está viuda y se dedica a labores domésticas, y da como referencia a Carlos Heubel, Cónsul de Alemania en la ciudad (36/78277).

Registremos la saga de los Pinnau, familia proveniente desde Hamburgo, cuya impronta en la ciudad, como hemos visto, la inició Carlos. Su hermano Guillermo Pinnau Bündel, llegó en 1908, casado con Berta Hartkop, y sus hijos Johan, casado con Amalia Hofmann, nacido en Hamburgo, se desempeñó como comerciante; Anne, nacida en la mencionada ciudad, se dedicó a labores de casa; Klaus, también nacido en Alemania, se desenvolvió en el comercio (34/2291, 60896, 26765, 63595).

Puede apreciarse en este listado que la colonia alemana no solo procede de modo preferencial desde Hamburgo, sino que las relaciones sociales declaradas muestran que las redes sociales de recepción también funcionaron como fuentes de información sobre las reales posibilidades que encontrarían en el desierto de Atacama.

¿Qué fue lo que decidió a los alemanes a la migración? Podemos apuntar a dos vertientes explicativas.

Ravenstein (1885 y 1889), sostuvo que los movimientos poblacionales, obedecen a motivaciones económicas, y que los desplazamientos de largas distancias eran realizados de preferencia por hombres, adultos, que se dirigían hacia los grandes centros de comercio o de la industria. Estos procesos coadyuvaban a que las grandes ciudades crecieran más por la inmigración que por incremento vegetativo y las 
migraciones se acrecentaban al verificarse un desarrollo económico con el progreso de la tecnología y el transporte (Arango, 1985). Si nos aproximamos a la decisión individual, Everett Lee (1966) planteó que dentro de una serie de factores, positivos y negativos, había que sopesar no sólo del lugar de origen, sino también del lugar de destino, como ser oportunidades de empleo, la calidad de vida, el clima, la disponibilidad de facilidades culturales y de ocio, la presencia o ausencia de trato discriminatorio y los factores de costo. A estos había que afrontar los obstáculos intervinientes, desde los físicos (montañas, océanos, desiertos) hasta los políticos, principalmente leyes de inmigración. En cuanto a los factores personales, el tercer factor esgrimido por Lee (1966), se ha considerado por Daugherty y Kammeyer (1995) que éstos pueden aludir, en un primer significado, a características de una persona o familia, tales como el tamaño de ésta o la fase en que se encuentra en el ciclo de la vida pero de igual modo, a la sensibilidad, inteligencia y conciencia de las condiciones en otra parte ("awareness of conditions elsewhere"), en un segundo sentido, al conocimiento, percepciones y conciencia del individuo migrante, donde éste debe justipreciar los valores positivos y negativos atribuidos a los lugares de origen y destino y, de igual manera, la percepción de los obstáculos intervinientes, pueden solamente tener significado cuando están presentes en la mente del migrante potencial (Daugherty y Kammeyer, 1995).

\section{Conclusiones}

La presencia alemana en el desierto de Atacama estuvo enmarcada en la denominada migración masiva europea, coincidente con la primera globalización. A diferencias de otros espacios geográficos, el páramo exigió a los alemanes sopesar las perspectivas económicas y de un proyecto de vida nuevo, quizás alejado de ciertas formalidades de ciudades ya consolidadas de América. Su apuesta de migrar fue, de acuerdo con la documentación, exitosa, pues logró contribuir a la fisonomía de la urbe, con su colaboración en las instituciones de gobierno local como de beneficencia pública, amén de encontrar un terreno propicio al espíritu de iniciativa privada, muy expresivo del liberalismo económico que animó los cateos y explotación de la riqueza minera del salitre y de la plata. El abastecimiento de la ciudad y del hinterland de Antofagasta, se vio favorecido por la apertura de un puerto que se constituyó en el segundo en 
importancia para los mercados mundiales de exportación del salitre.

Como en otras experiencias históricas, la migración alemana convivió con la sociedad local pero no se asimiló a ésta. Sus redes sociales funcionaron tanto como redes de recepción como de información para otros connacionales que tuvieron noticia de la industria del salitre y su porvenir puesto que la mayoría provino del principal puerto salitrero alemán, Hamburgo.

Las circunstancias históricas de las tensiones diplomáticas entre Chile y Bolivia, movieron a determinados migrantes alemanes a conjugar su postura política en convergencia con la defensa chilena de sus intereses mineros y de capitales. Las inversiones alemanas coincidieron con un segmento demográfico de mayor cualificación laboral que en otras ciudades chilenas, contribuyendo a consolidar una burguesía en el desierto de Atacama fundamentada tanto en sus intereses comerciales y mineros -y en cierta forma en los financieros-, como en su decidida intervención en las instituciones del gobierno local de Antofagasta. El análisis cualitativo denota la relevancia que logró la presencia alemana en casi todos los ámbitos de la vida pública de la naciente ciudad de Antofagasta, revelando cómo un porcentaje no despreciable de la emigración germana en el siglo XIX, fijó como residencia el entorno del desierto de Atacama, antípoda de su paisaje natal.

Su contribución queda realzada en el siglo XIX en tales ámbitos y en la construcción social de la principal ciudad del desierto de Atacama, reparándose en una omisión histórica en la literatura nacional y extranjera concerniente a la presencia alemana en América del Sur.

\section{Referencias}

Alarcón, C. (2014). El despertar de la maquinaria: Profesores y Oficiales chilenos en pos de la industrialización (1885-1920), Amérique Latine Histoire \& Memoire, 28. Les Cahiers ALHIM. Recuperado de http://alhim.revues. org/5037. 
Arango, J. (1985). Las leyes de las migraciones de E.G. Ravenstein, cien años después. Revista Española de Investigaciones Sociológicas, 32, 7-26.

Arce, I. (2004). Narraciones históricas de Antofagasta. Antofagasta: Corporación Pro-Antofagasta.

Archivo Histórico de la Universidad Católica del Norte: Archivo de Extranjería del Registro Civil e Identificaciones, Alemania, Cajas 31-36.

Archivo Histórico del Ministerio de Relaciones Exteriores de Chile (Santiago de Chile): Fondo Bolivia, volumen 39.

Barros, A. (2015). Revolución chilena, Litoral boliviano: La Patria, la Compañía de salitre y los prolegómenos de la Guerra del Pacífico en el desierto de Atacama (1870-1879), Antropología Experimental, 15(27), 483-520.

Bermúdez, O. (1966). Orígenes históricos de Antofagasta. Santiago: Prensas de la Editorial Universitaria.

Bernedo, P. (1999). Los industriales alemanes de Valdivia (1850-1914). Historia, $32,5-42$.

Bernedo, P. (1993). Las iglesias alemanas frente al problema de la emigración masiva, 1816-1914, Historia, 27, 69-87.

Bértola, L. y Ocampo, J.A. (2013). El desarrollo económico de América Latina desde la independencia. México: Fondo de Cultura Económica.

Billinghurst, G. (1889). Capitales salitreros de Tarapacá. Santiago de Chile: Imprenta El Progreso.

Blancpain, J. P. (1974). Les allemands au Chili: 1816-1945. Koln: Bohlau. 
Brahm, E. (2003). Preparados para la guerra. Pensamiento militar chileno bajo influencia alemana 1885-1930. Santiago: Ediciones Universidad Católica de Chile.

Condición actual de la propiedad salitrera en Chile y Estudio de las cuestiones relativas a la industria salitrera y a los salitrales del Estado presentado al señor Ministro de Hacienda por el Delegado Fiscal de Salitreras. Acompañado de 52 documentos y de un índice de las disposiciones oficiales relativas a la materia. 1892. Santiago de Chile: Imprenta Nacional.

Conservador de Bienes Raíces de Antofagasta, año 1880, volumen 7.

Conservador de Bienes Raíces de Antofagasta, Años 1880-1890. Vols. 7, 10, 13, 17, $21,25,33,37,46$.

Convenio celebrado entre las Policías de La Plata i Buenos Aires (Argentina), de Río de Janeiro (Brasil), de Santiago de Chile, de Montevideo (República Oriental del Uruguay), $N^{\circ} 180$, Santiago 18 de enero de 1906, Anuario del Ministerio del Interior correspondiente al año 1906. 1909. Santiago: Imprenta Nacional.

Daugherty, G. H. y Kammeyer, K. C. W. (1995). An Introduction to Population. New York: The Guilford Press.

Estrada, B. (2013). Importancia económica de los alemanes en Valparaíso. América Latina en la Historia Económica, 2, 151-176.

Folleto de las pertenencias salitreras del Toco, Aguas Blancas y Boquete. Antofagasta, 1905, Editado por los Talleres de la Imprenta de "El Comercio", Libros II, III, IV. Índice de los dueños de pertenencias salitreras i borateras concedidas por las autoridades bolivianas en el año 1873, sin foliar. Registro de los Peticionarios de pertenencias salitreras en Aguas Blancas, tomado de las notarías de Copiapó 1905, sin foliar. 
González, J.A. (2012). Matías Rojas Delgado, un pionero en el desierto de Atacama. En Matías Rojas Delgado, El Desierto de Atacama y el Territorio Reivindicado. Colección de artículos político-industriales publicados en la prensa de Antofagasta entre 1876 a 1882. Santiago: Biblioteca Fundamentos de la Construcción de Chile, $\mathrm{N}^{\circ}$. 48, pp. IX-LIV.

González. J.A. (2010). La influencia de la legislación municipal boliviana en Antofagasta, 1879-1888. Un capítulo desconocido en la historia del derecho público chileno. Revista Chilena de Historia del Derecho, 22(II), 913-937.

González, J.A. (2005). Chile y Bolivia (1810-2000). En P. Lacoste (Comp.), Argentina, Chile y sus vecinos, Tomo I. Mendoza: Caviar Blue Editora Andina.

Gould, J.D. (1979). European Inter-Continental Emigration. 1815-1915: Patterns and causes. Journal of European Economic History, 8, 593-679.

Guarda, G. (2011). Nueva historia de Valdivia. Santiago: Ediciones Universidad Católica de Chile.

Güenaga, R. (1989). La presencia alemana en el extremo austral de América. Jahrbuch für Geschichte von Staat, Wirtschaft und Gesellschaft Lateinamerikas, 26(1), 201-228. Doi: 10.7767/jbla.1989.26.1.201

Harris, G. (1997). La inmigración extranjera en Chile a revisión: también proletarios, aventureros, desertores y deudores, Anuario de Estudios Americanos, $\operatorname{LIV}(2)$, 543-566.

Hatton, T.J. y Williamson, J.G. (2006). What determines Immigration's Impact? Comparing Two Global Centuries. NBER Working Paper Series 12414 (July).

Hernández, R. (1930). El Salitre. Resumen histórico desde su descubrimiento y 
explotación. Valparaíso: Fisher Hermanos.

Índice de Peticionarios en salitreras de Taltal. 1905. Santiago: Imprenta La Ilustración.

Kellenbenz, H. y Schneider, J. (1976). La emigración alemana a América Latina desde 1821 a 1930. Jahrbuch für Geschichte von Staat, Wirtschaft und Gesellschaft Lateinamerikas, 13(1), 386-403.

Lee, E. (1966). A Theory of Migration, Demography, 3(1), 47-57.

Mandiola, J.L. y Castillo, P. (Eds.) (1894). Guía de Antofagasta de 1894. Avalúo definitivo de la propiedad mueble e inmueble de Antofagasta. Antofagasta: Imprenta El Industrial.

Marichal, C. (2011). Crisis financieras y debates sobre la primera globalización: reflexiones desde la historia económica latinoamericana. Mundo Siglo XXI. Revista del CIECAS-IPN, 25(VII), 5-14.

Musacchio, A. (2000). Los capitales alemanes en la Argentina en la década del 30. Jahrbuch für Geschichte von Staat, Wirtschaft und Gesellschaft Lateinamerikas, 37(1), 245-271.

Norambuena, C. (2003). El embrujamiento alemán, una polémica de fin de siglo. Cuadernos de Humanidades Nueva Época, 97, 29-40.

Notaría de Antofagasta. Año 1899. Vol. 99. Notario Carlos Lautaro Sayago.

Notaría de Antofagasta. Año 1899. Vol. 99. Notario Ramón Elizalde.

Notaría de Antofagasta. Año 1899. Vol. 97. Notario Vicente Villalón.

Notaría de Antofagasta. Año 1899. Vol. 96. Notario Vicente Villalón. 
Notaría de Antofagasta. Año 1898. Vol. 93.

Notaría de Antofagasta. Año 1897. Vol. 88. Notario Carlos Lautaro Sayago.

Notaría de Antofagasta. Año 1897. Vol. 85.

Notaría de Antofagasta. Año 1896. Vol. 79. Notario Enrique Rojas.

Notaría de Antofagasta. Año 1891. Vol. 48. Notario Hermógenes Cordero.

Notaría La Chimba. Año 1878. Vol. 17 y 18. Notario Belizario Campuzano.

O'Rourke, K. H. (2004). The Era of Free Migration: Lessons for Today. Discussion Paper. $N^{\circ} 18$, January. IISS Dublin, Ireland.

Oficina Central de Estadística, Sétimo censo jeneral de la población de Chile levantado el 28 de noviembre de 1895, Tomo I. 1900. Valparaíso: Imprenta Universo; Tomo II. 1902. Valparaíso: Imprenta Universo; Tomo III. 1903. Valparaíso: Imprenta Universitaria; Tomo IV. 1904. Valparaíso: Imprenta Universitaria.

Ojeda, G. (1980). El rol de la inmigración alemana en el proceso de formación de la nación chilena. Estudios Latinoamericanos, 7, 35-50.

Panadés, J.L. y González, J.A. (1998). Antofagasta, historia de mi ciudad. Antofagasta: Corporación Pro Antofagasta.

Penny, G. (2002). Objects of Culture. Ethnology and Ethnography in Museums in Imperial Germany. Chapel Hill: University of North Carolina Press.

Quinto Censo jeneral de la población de Chile levantado el 19 de abril de 1875 i compilado por la Oficina Central de Estadística. 1876. Valparaíso: Imprenta del Mercurio. 
Ravenstein, E.G. (1889). The Laws of Migrations. Journal of the Statistical Society of London, 52(2), 241-301.

Ravenstein, E.G. (1885). The Laws of Migrations. Journal of the Statistical Society of London, 48(2), 167-235.

Rebok, S. (2002). La constitución de la investigación antropológica alemana sobre América Latina a finales del siglo XIX. Revista de Indias, LXII(224), 195222.

Rinke, S. (2014). Germany and Brazil, 1870-1945: A relationship between spaces. História, Ciencias, Saúdes-Manguinhos, 21(1), 299-316.

Rinke, S. (1998). Las relaciones germano chilenas 1918-1933. Historia, 31, $217-$ 308 .

Rodríguez, H. (2001). Historia de la fotografia: Fotógrafos en Chile durante el siglo XIX. Santiago: Centro Nacional del Patrimonio Fotográfico.

Salinas, R. (1992). Una comunidad inmigrante: los alemanes en Valparaíso, 18601960 (Estudio demográfico). Jahrbuch für Geschichte von Staat, Wirtschaft und Gesellschaft Lateinamerikas, 29, 309-342.

Sanhueza, C. (2010). Circulación de intelectuales alemanes en Chile y chilenos en Alemania (Fines del siglo XIX y comienzos del siglo XX). Historia: Questoes \& Debates, 53, 67-84.

Sanhueza, C. (2006). Chilenos en Alemania y alemanes en Chile. Viaje y nación en el siglo XIX. Santiago: Editorial LOM - Centro de Investigaciones Diego Barros Arana.

Taylor, A.M. y Williamson J.G. (1994). Convergence in the Age of Mass Migration. NBER Working papers Series $N^{\circ}$ 4711. National Bureau of Economic 
Research, Cambridge MA. USA.

Vera, M.C. (1994). Emigraciones transoceánicas. Los alemanes en América. 18501914. El caso argentino. Cuadernos de Historia Contemporánea, 16, 65-98.

Vicuña Mackenna, B. (1880). Historia de la campaña de Tarapacá: desde la ocupación de Antofagasta hasta la proclamación de la dictadura en el Perú. Santiago: Rafael Jover, Editor. 